\title{
Analysis on the present situation of higher education reform in China
}

\author{
Zhang YunLing
}

Xi'an International University, Xi'an, 710077, China.

Keywords: higher education; talent training; quality of Education

\begin{abstract}
How to solve the deep-seated contradictions and problems and improve the quality of higher education, has been the subject of the higher education reform. The development stage of higher education now is to scale growth as the center to change in order to improve the quality of the core, improve the quality of covering all aspects, involving many interests, cannot rely on unilateral reform advancement and completion. From the talents training system reform, the reform of the management system, investment system reform, the reform of scientific research system, starting with the reform of the personnel system, the status quo of Chinese higher education reform through the analysis of the status quo is complex and comprehensive, involving many aspects of system, need to continue to advance China's entry into the building. Setting up a well-off society and deepening reform and opening up, accelerate the transformation of the way of economic development in the crucial period, improve the quality of higher education is imminent.
\end{abstract}

\section{Introduction}

The reform and development of higher education in China has made the expansion of the scale, the number of supply mainly has entered a new stage in order to improve the quality and level of development oriented, is "to seek" strategy to "shift to quality and strong" strategy. To improve the quality of talent training, providing high-quality education resources supply capacity and the level becomes the core task of current the reform of higher education. How to solve the deep-seated contradictions and problems and improve the quality of higher education, has become the subject of the higher education reform. The reform of the talent cultivation system, the reform of the management system, investment system reform, the reform of scientific research system, the reform of the personnel system, it is a complicated and comprehensive, involving many aspects, require the system to Continued to promote change. Exhibition brings about changes in the reform of the task, the reform task. At present, the deepening of reform and opening up China entering a crucial period of building a well-off society, accelerate the transformation of economic development in the crucial period, the importance in improving the quality of higher education and the urgency of the more prominent.

Personnel training is the essential requirement of higher education and the fundamental mission. The first standard to measure the quality of higher education is to see the level of talent training, the core is to solve what people to cultivate, how to train people on major issues. We must firmly establish a talent training center in the University, all work must obey and serve the growth of students talent, and resolutely reverse the teaching scientific research subject, heavy light phenomenon, focus on improving the student services National People's sense of social responsibility, the courage to explore the spirit of innovation, problem-solving practical ability, cultivate socialist builders and successors of all-round development.

\section{Guide teachers to devote themselves to educating people, to create a high level of teaching staff.}

Teachers are the first resource of the education, is the key to determine the quality of education. Now teacher education levels improved significantly, but there is still a source of diversification of the structure of teachers is not reasonable, professional quality and ethics level needs to be improved. A few teachers did not handle well the relationship between teaching and educating, 
teaching, scientific research and social relations the level of education can not be guaranteed. We should take the construction of teachers as the most important foundation engineering to grasp.

\section{Deepen the reform of education and teaching, and strive to improve the level of personnel training.}

Teaching quality is the core standard to measure the level of education, years of education reform has made some progress, but there are still some schools are teaching philosophy behind the old teaching method, lack of students' scientific thinking training, to stimulate students' enthusiasm for academic research, some students narrow range of knowledge, comprehensive quality and adaptability is not strong. It is imperative to accelerate the teaching reform.

One needs to innovate the teaching idea and mode of talent training. Rucker first, Li Xue based, it is necessary to strengthen the professional education, pay attention to the "thick foundation, wide field, wide adaptability, strong ability, but also to strengthen the ideological character education, pay attention to the" tree of ideal, strong willed, brave practice, dedication ", make the students has the firm ideal faith, vision of the mind, to better meet the needs of future occupation and social development. To explore the scientific basis, practical ability and ideological and moral cultivation mode, integration and development of humanistic quality, promote inter college, interdisciplinary, interdisciplinary cross culture in Colleges and universities, research institutes, enterprises joint education.

Two to innovative teaching methods and means. At present, some universities still daunted, cramming method of teaching, some college courses but challenging problems, some college classroom is more and more big, the public course of several hundred people, interactive discussions more difficult. To encourage the development of small class teaching, heuristic, discussion, participatory teaching students in creative thinking should be inspired and encouraged in the whole process of teaching.

Three to innovative learning methods. With the development of modern society, university learning appears many new features, independent learning, inquiry learning and lifelong learning concept has been widely recognized. But many students still take the scores, diploma as the main purpose of learning, lack of independent learning spirit. To establish students in learning the subject position, gradually change the knowledge type teaching mode with the teacher as the center, opened by the teachers and students common topics of the autonomous learning curriculum, strengthen the construction of multiple modes of learning, learning strategies and methods of training, cultivating students' critical thinking and innovation ability, promote the development of personality.

\section{Improve the scientific research, social services and cultural heritage innovation capability, the formation of mutual support, the overall quality of the pattern.}

The function of modern university has been extended to personnel training, scientific research, four aspects of social services and cultural innovation, implement the strategic task of increasing quality, must take the personnel training as the core, the four functions of the organic interaction, mutual support, open the connotation of greater development space.

To strengthen scientific research, promote collaborative innovation. Collaborative innovation is both an important way to enhance national innovation ability, but also the inevitable requirement of cultivating innovative talents, promote the scientific research ability. In order to promote the reform of scientific research "cooperation" concept, breaking the closed and scattered pattern, play multi discipline and multi function advantage, promote the organic integration of innovative elements and the comprehensive sharing.

The two is to expand the social services, strengthen practice and training. Students in the social practice of basic education at the university level is relatively small, need to fill this lesson. But the practice education mechanism still need to be improved, there is inadequate attention, inadequate investment, lack of social problems with university students through social service training opportunities and channels do not. The government should improve the relevant policies and 
regulations, the purchase of services through financial support, tax incentives and other ways to support the practice of educating people, strengthen the practice teaching platform construction, support the formation of the social practice of the network.

Three to strengthen the cultural inheritance and innovation, to participate in the construction of cultural power. Universities are the important position of Ideological and cultural innovation, it has the double advantage of cultural education personnel and Xing culture with talent, but some university cultural inheritance and innovation function has not been demonstrated, people with culture concept is not integrated into the whole process of education and teaching, must be in accordance with the requirements the party's the sixth Plenary Session of the 17th CPC Central Committee, force to play the role of cultural development and prosperity, and make greater contributions to the construction of cultural power. To encourage teachers and students to join the culture of innovation to create the record of social life and people's spiritual world, creation reflect more flourishing style of fine works, provide better and more refined for the society God of food, but also to enable students to enhance the humanities spirit and character in cultural creation. To promote the development of philosophy social science, strengthen the experience and theory innovation of the great practice of socialism Chinese, consolidate the development of Marx's theory of discipline, promote the socialist core value system construction.

\section{To promote the university students' self employment}

To reform the training modes of talents in Colleges and universities. From now until 2020, China will have about 45000000 college graduates, even at the current entrepreneurship rate, will also have at least millions of college graduates walk the road of entrepreneurship. Their entrepreneurial capabilities and entrepreneurial levels, crucial to development of our country in the future. In the respect of university autonomy according to law on the basis of the school, encourage the university to continue to deepen reform, innovating the mode of talent training, and guide more college students to walk the road of entrepreneurship. Colleges and universities should adapt to the needs of the construction of an innovative country, advanced design more flexible learning system and learning mode, offer more entrepreneurial guidance courses, To attract more entrepreneurial guidance teachers, arrange more entrepreneurial training base, and strive to improve the level of entrepreneurship education in Colleges and universities.

Two to increase entrepreneurship policy support. The cultivation of College Students' entrepreneurial ability, government support is also very important. According to the survey, a current problem hinder entrepreneurship is very prominent, is the lack of venture capital support. The existing funding policies because the amount is low, formalities trouble, difficult to guarantee, causing many qualified students to give up the application. Relatives and friends to borrow. The government should increase policy support efforts to increase the amount of venture capital and benefit, industry and commerce, taxation, social security and other departments should better take the responsibility of the departments in charge of policy, increase information transparency, simplify examination and approval procedures, relaxed operating conditions, to attract social funds risk To create conditions for more students and provide convenience. The Department in charge of education should not only focus on the level of employment, but also attach importance to the graduates of entrepreneurship, entrepreneurship training to do a good job in Colleges and universities should sum up experience, timely, timely promotion, give full play to creative industry promoting employment multiplier effect.

Three to optimize the entrepreneurial social environment. Good social entrepreneurial culture and entrepreneurial environment, is an important incubator and propeller. Students should encourage more entrepreneurs into the University, into the classroom, and students who share entrepreneurial motivation more sour, sweet, bitter, hot, walk the road of entrepreneurship. Students should be encouraged to set up more social venture capital funds in Colleges and universities, the establishment of entrepreneurial guidance of professional bodies, according to the college student entrepreneurs need to provide business, technology, finance, business, finance, law and all aspects of logistics and other professional services. To optimize the investment environment, to create a 
business platform, vigorously strengthen the construction of entrepreneurial culture in the society. On the real formation of a kind of courage to start a business, respect for entrepreneurship, innovation, tolerance of failure of the social fashion.

\section{The construction of the fine style of teaching ethos, form a good environment conductive to the cultivation of talents.}

Culture is the soul of a university, but also an important symbol of university characteristic display. Many Chinese and foreign schools, each building contains the weight of history, every tree and bush are permeated with rich cultural atmosphere. But some magnificent, but university edifice, feeling a lack of culture. The university culture is accumulated in the long time running the core is the spirit of the University, outside into the style of teaching ethos, as an important task to improve the quality, the culture is more rich, the spirit of quality more outstanding, the formation of a good atmosphere for education.

One should firmly adhere to the socialist core value system as the guidance. Universities should deeply understand the connotation of the socialist core value system, the combination of school and traditional school of thought, and actively cultivate the distinctive university spirit, vigorously promote respect for science, to explore the truth, independent thinking, innovation, dedication to the community spirit, formed a unique cultural realm of noble. Deep inside, motivate and lead the connotative development. To carry out the ideals and beliefs education, education policy, the situation of national education, traditional education, education reform, national defense education, national unity education, encourage students to have the motherland, love the people, forge ahead, Fen Promising, ideological identity and emotional identity of Chinese socialism, growth for the country and the nation's a man of tremendous promise.

Two to strengthen the campus culture and brand culture construction. The cultural atmosphere in shaping students' Humanistic Quality in the invisible, the effect of accumulation on human life lasting. Attention should be paid to the motto of song, the construction of campus culture carrier theme activities, vigorously carry out cultural activities healthy and active, forming a coagulating effect on teachers have cultivate role for students, have a demonstration effect of the campus culture on society. To promote the network dissemination of excellent traditional culture and modern culture, the campus network has not only become the students' cultural life and ideological education platform, has become a new social space to spread advanced culture.

Three to strengthen the academic integrity and academic discipline. The academic atmosphere of the University mainstream positive, but there are even impetuous academic atmosphere of academic corruption, need to start from the cultural and institutional level, strengthen the construction of academic integrity, cultivate good academic tradition. To honesty education should be included in the curriculum content into teacher occupation training, to enhance the scientific and moral standards to lay a solid foundation. At the same time, strictly comply with academic standards, improve academic management, adhere to the facts, of research misconduct punch, zero tolerance, make the university really become a sacred place of academic integrity, social heights.

\section{Conclusions}

To carry out comprehensive reform in the field of education, improve the education service level of social economic development, is the development of the national economy, the urgent need of deepening the reform of higher education. At present, China has been standing at a new historical starting point, seize the opportunity, deepen the comprehensive reform of higher education, higher education is the inevitable requirement of deep crack contradictory. Higher education has realized the great leap of popularization, has entered a new stage of development. The construction of soft environment especially in the governance structure, personnel system, personnel training mechanism, scientific research system, restricted by resource constraints on growing, if not a comprehensive deepening of reform, the development mode A breakthrough, it is difficult to get rid of the traditional relatively closed, extensive resources development mode, the quality of personnel 
training and scientific and technological innovation ability will be very difficult to have a new upgrade. China in each school are not the same situation, promote the comprehensive reform of higher education, we must fully reflect the diversity of the actual in combination with the school and explore different models. We must clearly recognize that the institutional reform is the reform of other locomotive drive forward in an orderly way, through the system construction, the effective coordination of Party committees and administrative relations, relationship between the school and the faculty, the relationship between teaching and research, the relationship between teachers and students, the center The relationship between work and logistical support of the relationship, so that the organic unity of the educational elements to form a cohesive force, realize the modernization of governance capacity and governance structure, the way of content development to improve the quality as the core, so as to improve the quality of higher education.

\section{References}

[1] Luo Yongjin. The development trend of higher education in China . 21 century.2001.3.

[2] Zhou Dingcai. "After 90" College Students' psychological behavior characteristic and the education management countermeasure. The University Education Management. 2011.5.

[3] Wu Daguang. Higher education management. education and the correlation of the reform of the investment system of higher education research. 1999.2.

[4] Yan Yan. Study on the network public opinion in group events [M]. Beijing: Xinhua Publishing House, 2013,20-25.

[5] Shi Cuixian, Yan Liping, Jin Lan. The government how to deal with the network public opinion research talent crisis [J]., 2011 (6), 15-30.

[6] Miao Zhuang. Group events of the network public opinion guide [J]. youth reporter, 2010 (5), 18.

[7] Li Qiongyao. Current situation and guidance of network public opinion. Journal of Hunan Administration College, 2006 (2), 6-28.

[8] Jiang Sheng hong. The status quo of China's Internet public opinion and its guide [J]. Guangxi social science, 2009 (L), 26. 